\title{
Contribution of Arab countries to breast cancer research: comparison with non-Arab Middle Eastern countries
}

\author{
Waleed M Sweileh"* Sa'ed H Zyoud², Samah W Al-Jabi and Ansam F Sawalha'
}

\begin{abstract}
Background: Breast cancer is one of the most common types of cancers affecting women worldwide. The main objective of this study was to assess and compare research activity in breast cancer in Arab countries with non-Arab Middle Eastern countries.

Methods: Publications about "breast cancer" as a research topic were retrieved using the ISI Web of Science database. Analysis was confined to original research and review articles. Research productivity was assessed by assessing number of publications and time trend of these publications, names of journals, citation analysis, top 10 active institutions as well as country contribution to breast cancer research. The quantity and quality of publications from Arab countries in addition to 3 other Middle East countries (Turkey, Iran and Israel) were assessed and compared using the $h$-index tool.

Results: A total of 1658 original research and review articles about "breast cancer" were published from Arab countries. Annual research productivity from Arab countries in the field of "breast cancer" was negligible but showed a significant increase in the last decade. Retrieved documents had relatively high citation parameters as measured by h-index of 61 and average citations of 17.46 per document. The highest research productivity was from Egypt with a total publication of 582 (35.10\%). Cairo University with a total of 149 (8.99\%) publications had the highest research productivity among institutions in Arab world. Forty four documents (2.65\%) of breast cancer documents were published in Saudi Medical Journal. Arab researchers collaborated mostly with researchers from the United States of America $(305 ; 18.40 \%)$ in breast cancer research. Compared with other non-Arab Middle Eastern countries, Arab countries had higher research productivity than some countries and lower than others, particularly Israel.
\end{abstract}

Conclusions: The present data reveals a good contribution of some Arab countries to the field of "breast cancer" research. There is a gap between Arab countries and Israel in the quality of breast cancer research.

Keywords: Bibliometric, Breast cancer, Arab world, Middle Eastern Region, ISI Web of Science

\section{Background}

Breast cancer is one of the most common types of cancers among women in the Arab world [1]. Research in general and in breast cancer in particular is important for each country in order to understand the cultural and genetic differences among different people in different geographical areas. Therefore, assessing research about breast cancer from Arab countries has an important impact on the future policies in the fight against such an

\footnotetext{
* Correspondence: waleedsweileh@yahoo.com

'Department of Pharmacology and Toxicology, College of Medicine and Health Sciences, An-Najah National University, Nablus, Palestine

Full list of author information is available at the end of the article
}

emotionally disturbing type of cancer. In addition, no doubt that high research activity in breast cancer can reflect positively on screening programs, awareness, epidemiological data and clinical practice. Assessing research activity in any subject in any geographical region is not an easy task given the diversity of academic databases and indexing methods of such databases. One of the most commonly utilized methods to assess research activity is known as bibliometric methods which have been applied to various medical subjects in different countries [2-8]. No doubt that the Arab world have witnessed great progress in the past few decades in medical education and medical practice including establishing



(c) 2015 Sweileh et al.; licensee BioMed Central. This is an Open Access article distributed under the terms of the Creative Commons Attribution License (http://creativecommons.org/licenses/by/4.0), which permits unrestricted use, distribution, and reproduction in any medium, provided the original work is properly credited. The Creative Commons Public Domain Dedication waiver (http://creativecommons.org/publicdomain/zero/1.0/) applies to the data made available in this article, unless otherwise stated. 
high standards private hospitals and private medical colleges. Furthermore, many governments in the Arab world, particularly in the Arab Gulf, have financially endorsed the development of medical research and practice to serve the general public health of their people. The Arab world has an overall population of around 380 million and extends over a large geographical area in northern Africa and Middle East. Our research group have previously published several bibliometric studies in different medical disciplines like osteoporosis, diabetes, toxicology and others [9-11]. In this study, our research group is trying to shed light on a very important health topic pertaining to women's health and public health as well which is breast cancer research activity in Arab countries. The objective of this study was to assess publication trend in Arab countries in breast cancer and compare it with non-Arab Middle Eastern countries. Such study will give an insight into research activity and will encourage those in the field of breast cancer.

\section{Methods}

The methodology as well as the tool used in this study were discussed in previous publications by the same group $[11,12]$. The tool used was ISI Web of Science (WoS) [13]. The method used in this study is similar to the method used by the authors in their previous publications $[11,14,15]$. For the purpose of this study, WoS is preferred over PubMed because PubMed does not allow for citation analysis. Similarly, WoS is preferred over Scopus because WoS includes the most influential and prestigious journals in all medical fields. All Arab countries were used as country keys followed by "breast cancer" phrase as a topic. We focused on the phrase "breast cancer" as search topic (TS) and excluded any other associated phrases like "mammary ducts" because we are interested in breast cancer per se rather than associated cancers. Because the WoS database does not recognize Palestine as an independent state yet, search for breast cancer documents from Palestine was carried out using separate search keys. The results from 21 Arab countries and those from Palestine were combined and the resultant data were analyzed. Only original research articles and review articles were included in the analysis. Furthermore, analysis was made up to year 2012 while 2013 and 2014 years were excluded because they are still open for new journal issues. The standard competition ranking (SCR) was used to present the top 10 ranking data while journal's impact factors (IF) were evaluated using the Journal Citation Report (JCR; Web of Science) 2013 science edition by Thomson Reuters (New York, NY, USA).

\section{Results}

The total number of worldwide publications in breast cancer retrieved from Arab countries was 1658 publications while worldwide number was 206,710. Therefore, "breast cancer" research output from Arab countries represents $0.8 \%$ of the global research productivity in "breast cancer". The first article about breast cancer co-authored by an Arab researcher was published in 1977 in Cancer Journal and the title of the article was: "Clinical and prognostic features of a rapidly progressing breast-cancer in Tunisia".

The annual number of publications from Arab countries indicated that "breast cancer" research output remained low until mid-1990s and showed a significant increase in the last three years. Approximately 50\% of breast cancer documents from Arab countries were published in 2010, 2011 and 2012. Figure 1 shows the annual growth of breast cancer research documents from Arab countries. When retrieved data were analyzed by country, Egypt $(582 ; 35.10 \%)$ had the highest research output followed by Kingdom of Saudi Arabia (372; 22.44\%) and Tunisia (172; 10.37\%). No data related to breast cancer was found from Somalia, Djibouti, Mauritania and Comoros (Table 1). The language of most breast cancer documents published from Arab countries was English (1589; 95.84\%) while the remaining documents were published in French language (69; 4.16\%). One hundred and ninety three (11.64\%) documents were open access while the remaining (88.36\%) were not open access. Countries whose researchers collaborated most in breast cancer research with investigators in the Arab world include the United States of America (USA); (305; $18.40 \%)$ followed by France $(139 ; 8.38 \%)$ and England (132; 7.96\%).

The total number of citations for breast cancer documents from the Arab world, at the time of data analysis, was 28,953 with an average citation of 17.46 per document. Of the 1658 documents considered for the $h$-index, 61 had been cited at least 61 times at the time of data analysis. When stratified by country, the $h$ index was highest for breast cancer documents published from Egypt $(h$-index $=43)$ followed by those published from KSA ( $h$-index $=31$ ) and Tunisia $(h$-index $=26)$. Of the 1658 breast cancer documents published from Arab countries, there were $660(39.81 \%)$ documents in the oncology research area, 185 (11.16\%) in the pharmacology/ pharmacy research areas, and 128 (7.72\%) documents in Biochemistry/Molecular Biology. Other research areas found in published documents from the Arab countries are shown in Table 2.

Table 3 lists the top 10 journals in which documents in breast cancer were published from Arab countries. Forty four (2.65\%) breast cancer documents from Arab countries were published in Saudi Medical Journal which is a non-oncology journal. Of the top 10 journals in which breast cancer documents were published from the Arab countries, only 1 journal (International Journal of cancer Research) had an impact factor $>5$. Table 4 




Figure 1 Annual growth of breast cancer research output from Arab countries, Turkey, Israel and Iran. Earlier data were not shown in the figure because it is almost approaching zero for most Arab countries.

shows the top 10 most productive Arabic institutions in breast cancer. The most productive institution was Cairo University (149; 8.99\%) followed by King Saud University $(117 ; 7.06 \%)$. Eight institutions in the top 10 list are academic institutions affiliated with teaching hospitals that have oncology departments.

Compared with other non-Arab countries in the Middle East, the research productivity from the Arab countries was lesser than that from Israel and Turkey but higher than that from Iran (Figure 1). The $h$ index of breast cancer documents published from Arab countries was higher than that of Turkey and Iran but was much lower than that from Israel. The journal with the highest number of breast cancer documents published from Arab countries was Saudi Medical Journal (IF of 0.55); that from Turkey and Iran was Asian Pacific Journal of Cancer Prevention (IF = 1.50), while that from Israel was Journal of Cancer Research (IF = 9.28); (Table 5). The annual growth of breast cancer research output from Arab countries, Israel, Turkey and Iran is shown in Figure 1. Breast cancer research in Israel started as early as 1973 and showed a continuous momentum since then. However, breast cancer research in Arab countries, Turkey and Iran started breast cancer research after 1977 and showed great fluctuations up until mid-1990s. Regarding research interests, biochemistry/ genetics and cell biology constituted approximately $25 \%$ of breast cancer documents from Israel but less than 10\% in Arab countries or Turkey or Iran. Finally, it should be noted that of the documents published from Israel, there were 16 documents about breast cancer in Israeli Arab women, either in comparison with Jewish women or being investigated as a separate cultural group.

\section{Discussion}

In this study, we assessed the research activity about breast cancer from Arab countries. We used the ISI web of science database as a method to assess research activity. Up to the author's best knowledge, this is the first bibliometric study to assess breast cancer research activity from Arab world. Bibliometric studies that assessed global breast cancer research productivity has been previously published but with no detailed emphasis on Arab region $[16,17]$.

The result indicated that 1658 documents in breast cancer were published from Arab countries up to year 2012. This number is an important piece of information for future analysis and for health policy makers. It should be emphasized that some journals in which Arab researchers have published about breast cancer are not indexed in ISI web of science. For example, articles pertaining to breast cancer that were published in Journal of the Egyptian National Cancer Institute or Eastern Mediterranean Health Journal were not considered in 
Table 1 Contribution of each Arab country to the 1658 breast cancer published documents

\begin{tabular}{|c|c|c|}
\hline Country & $\begin{array}{l}\text { Number of documents } \\
N(\%)=1658(100 \%)^{*}\end{array}$ & $h$ index \\
\hline Egypt & $582(35.10)$ & 43 \\
\hline Kingdom of Saudi Arabia & $372(22.44)$ & 31 \\
\hline Tunisia & $172(10.37)$ & 26 \\
\hline Kuwait & $121(7.30)$ & 21 \\
\hline Lebanon & $120(7.24)$ & 23 \\
\hline United Arab Emirates & $89(5.37)$ & 22 \\
\hline Jordan & $79(4.76)$ & 18 \\
\hline Morocco & $73(4.40)$ & 15 \\
\hline Qatar & $32(1.93)$ & 11 \\
\hline Algeria & $27(1.63)$ & 9 \\
\hline Sudan & $21(1.28)$ & 6 \\
\hline Iraq & $21(1.28)$ & 7 \\
\hline Libya & $20(1.21)$ & 6 \\
\hline Syria & $18(1.09)$ & 8 \\
\hline Yemen & $17(1.03)$ & 7 \\
\hline Oman & $13(0.78)$ & 7 \\
\hline Palestine & $10(0.52)$ & 6 \\
\hline Bahrain & $7(0.42)$ & 3 \\
\hline Somalia & $0(0.0)$ & 0 \\
\hline Comoros & $0(0.0)$ & 0 \\
\hline Djibouti & $0(0.0)$ & 0 \\
\hline Mauritania & $0(0.0)$ & 0 \\
\hline
\end{tabular}

*total exceeds $100 \%$ because of overlap in some documents among more than one Arab country.

Table 2 Research areas of the 1658 breast cancer documents published from the 22 Arab countries

\begin{tabular}{lll}
\hline SCR $^{\mathbf{a}}$ & Research area & $\begin{array}{l}\text { Number (\%) } \\
\mathbf{N}=\mathbf{1 6 5 8}(\mathbf{1 0 0 \% )}\end{array}$ \\
\hline 1st & Oncology & $660(39.81)$ \\
2nd & Pharmacology Pharmacy & $185(11.16)$ \\
3rd & Biochemistry Molecular Biology & $128(7.72)$ \\
4th & Pathology & $103(6.21)$ \\
5th & General Internal Medicine & $101(6.09)$ \\
6th & Chemistry & $94(5.67)$ \\
6th & Obstetrics Gynecology & $94(5.67)$ \\
8th & Cell Biology & $89(5.37)$ \\
9th & Radiology Nuclear Medicine Medical Imaging & $74(5.49)$ \\
10th & Surgery & $54(3.26)$ \\
\hline
\end{tabular}

Abbreviation: SCR = Standard Competition Ranking.

${ }^{a}$ Equal research areas have the same ranking number, and then a gap is left in the ranking numbers.
Table 3 Top 10 journals in which breast cancer documents from the 22 Arab countries were published

\begin{tabular}{llll}
\hline SCR $^{\mathbf{a}}$ & Journal & $\begin{array}{l}\text { Number (\%) } \\
\mathbf{N = 1 4 5 6}\end{array}$ & IF $^{\mathbf{b}}$ \\
\hline 1st & Saudi Medical Journal & $44(2.65)$ & 0.554 \\
2nd & Asian Pacific Journal of Cancer Prevention & $41(2.47)$ & 1.50 \\
2nd & Breast Cancer Research and Treatment & $41(2.47)$ & 4.19 \\
4th & Anticancer Research & $38(2.29)$ & 1.872 \\
5th & Breast & $25(1.51)$ & 2.581 \\
6th & European Journal of Medicinal Chemistry & $24(1.45)$ & 3.432 \\
6th & Medical Oncology & $24(1.45)$ & 2.058 \\
9th & Life Science Journal Acta Zhengzhou & $22(1.33)$ & 0.165 \\
& University Overseas Edition & & \\
10th & Cancer & $20(1.21)$ & 4.901 \\
10th & International Journal of Cancer & $20(1.21)$ & 5.007 \\
\hline
\end{tabular}

Abbreviations: $\mathrm{SCR}=$ Standard Competition Ranking; $\mathrm{NA}=$ not available; $\mathrm{IF}=$ impact factor.

${ }^{a}$ Equal journals have the same ranking number, and then a gap is left in the ranking numbers.

${ }^{\mathrm{b}}$ The impact factor was reported according to Institute for Scientific Information (ISI) journal citation reports (JCR) 2012.

the analysis since these journals are not listed in the WoS. Therefore, the result obtained might be lesser than the actual research activity in Arab countries. Despite that, our study reflects a close approximation of breast cancer research activity in the Arab world and that is present in international and reputable journals. The ISI of Web of Science gives a powerful and attractive citation analysis for bibliometric studies. Furthermore, the ISI Web of Science database reflects publications in journals which have scientific and international impact as well as large audience and readers in the field of breast cancer.

Table 4 Top 10 active institutions in breast cancer research in Arab countries

\begin{tabular}{llll}
\hline SCR & Institution & $\begin{array}{l}\text { Number (\%) } \\
\text { N= 1658 }\end{array}$ & Country \\
\hline 1st & Cairo University & $149(8.99)$ & Egypt \\
2nd & King Saud University & $117(7.06)$ & KSA \\
3rd & $\begin{array}{l}\text { King Faisal Specialist Hospital } \\
\text { Research Center }\end{array}$ & $115(6.94)$ & KSA \\
4th & Kuwait University & $104(6.27)$ & Kuwait \\
5th & American University of Beirut & $83(5.01)$ & Lebanon \\
6th & Alexandria University & $56(3.38)$ & Egypt \\
7th & Mansoura University & $53(3.20)$ & Egypt \\
8th & Ain Shams University & $47(2.84)$ & Egypt \\
9th & Assiut University & $46(2.97)$ & Egypt \\
10th & National Research Center & $45(2.71)$ & Egypt \\
\hline A6briations
\end{tabular}

Abbreviations: SCR $=$ Standard Competition Ranking; KSA = Kingdom of Saudi Arabia. 
Table 5 Breast cancer research output from Arab countries compared with that from Turkey, Israel, and Iran

\begin{tabular}{|c|c|c|c|c|}
\hline Data/Country & 22 Arab countries & Turkey & Israel & Iran \\
\hline Number of population in millions & 380 & 60 & 8 & 80 \\
\hline $\begin{array}{l}\text { Number of published research } \\
\text { articles and review articles }\end{array}$ & 1658 & 2025 & 2440 & 731 \\
\hline Total number of citations & 28,953 & 22,438 & 96,323 & 7807 \\
\hline Average citation per document & 17.46 & 11.08 & 39.48 & 10.68 \\
\hline h-index & 61 & 56 & 128 & 37 \\
\hline $\begin{array}{l}\text { Country with the highest } \\
\text { collaboration (\%) }\end{array}$ & USA $18.40 \%$ & USA 8.64\% & USA $26.11 \%$ & USA 6.98\% \\
\hline $\begin{array}{l}\text { Journal with the highest } \\
\text { publication (N); (IF) }\end{array}$ & $\begin{array}{l}\text { Saudi Medical Journal (44) } \\
\text { IF = } 0.554\end{array}$ & $\begin{array}{l}\text { Asian Pacific Journal of Cancer } \\
\text { Prevention (78) IF }=\mathbf{1 . 5 0}\end{array}$ & $\begin{array}{l}\text { Cancer Research }(87) \\
\mathbf{I F}=\mathbf{9 . 2 8}\end{array}$ & $\begin{array}{l}\text { Asian Pacific Journal of Cancer } \\
\text { Prevention (64) IF = } \mathbf{1 . 5 0}\end{array}$ \\
\hline
\end{tabular}

Breast cancer is one of the most emotionally devastating types of cancers for women all over the world. One of the best methods to combat breast cancer and improve the quality of life of women in Arab world is to do breast cancer screening surveys. Unfortunately, it has been reported that breast cancer screening participation rates are low among women in the Arab world [18]. Efforts to combat breast cancer at the global and regional levels should be collective and all those in field need to contribute in this fight against breast cancer at all levels. Research is an important aspect and contribution that can help in combating breast cancer globally and at the regional level. The importance of regional research about breast cancer stems from the fact that cultural and genetic variations might affect breast cancer disease profile among women in different regions and countries.

Our results showed that breast cancer research was neglected in most Arab countries during the 1970s and 1980s. Despite the valuable contribution of Arabs to medicine throughout history [19], reports indicated that medical research activity in Arab world is still lagging behind compared to non-Arab countries in the region like Israel, Turkey or Iran [9,20-24]. Until the time of writing this manuscript, breast cancer research activity is considered low in many Arab countries including those with good economy like Bahrain. On the other hand, breast cancer research in Egypt and KSA showed a steep rise in the past decade. Actually, some of the research activity in Egypt and KSA was governmentally funded suggesting a national policy to promote cancer research as one preventive strategy to combat this devastating type of cancer. Our findings regarding research activity from Egypt and KSA might not be surprising given that previous research indicated that Egypt and KSA have high biomedical research output [24,25]. Low research activity in some Arab countries is a multi-faceted problem that could be attributed at least in part to, inadequate research infra- structure in many cancer institutions in these countries, the modest governmental and nongovernmental funding, in addition to a poor cooperation between industry and academia. Governments in the Arab world need to consider these factors if they wish to improve the status of their scientific research [24,26-28].

Our study indicated that the average citation per breast cancer document from Arab world was 17.46. This is relatively a high number and suggests that there is a growing interest in breast cancer from the Arab world and that competition in this field is growing as well. Highly cited articles positively contribute to the $h$-index of the individual author and to the institution and country [29-32]. The citation is a key indicator of research quality [33]. The h-index simultaneously measure the quality and quantity of scientific output. However, $h$-index measured using different databases can give different values and therefore each database has pros and cons when measuring the h-index [34-36]. Criticisms have also been addressed to the use of $h$-index as a marker of publication quality and citation. For example, the h-index does not consider the context of citations, the number of authors in the document, and gives equal values for book citation and research citation. Therefore, the $h$-index has lesser predictive accuracy and precision than mean citations per paper, although this is controversial $[37,38]$.

In our study, the $h$-index of breast cancer documents published from Israel was higher than that for breast cancer documents published from Arab countries or Iran or Turkey. One possible reason for this is the impact factor of journals in which Israeli researchers publish their breast cancer research. Israeli researchers with high quality research tend to publish their research in high impact factor journals like Cancer Research Journal. Such publications in high impact journals might have increased the citations for Israeli publications in the field of breast cancer $[39,40]$. When submitting a manuscript for publications, authors are 
usually inclined to submit to journals that are publication free, follow open access policy, preferably have a high impact factor, and above all have a short editorial and revision time [41,42]. Researchers from Arab world have preferred publishing breast cancer research in Saudi medical Journal. This medical journal poses no publication fee and represents an open forum for medical research discussions in the Arab world.

Our results showed that authors from Arab and nonArab countries like Israel, Turkey and Iran collaborated mainly with authors from the USA in breast cancer research. International collaboration is beveled to increase the quantity and quality of research activity [43-45]. Breast cancer research in Israel was evidently better than that from Arab countries in quantitative and qualitative terms. One possible reason for this is the intensive collaboration between Israeli and the USA researchers in the field of breast cancer. One explanation for this intensive collaboration between Israeli and the USA researchers is the fact that the status of cancer research in Israel is parallel to that in the USA. Collaboration in research activity can increase the visibility, quantity and quality of research output from any particular country or institution [46-50].

Our study has points of strength and points of weaknesses. This is the first study in the Arab world to investigate and assess breast cancer research activity. The study showed that only few Arab countries, particularly Egypt and KSA had good research output in breast cancer while other Arab countries had limited research activity in this field. Of course, this study does not mean to negatively criticize research activity in any particular country, rather it meant to draw attention and encourage researchers in this field. Finally, it should be mentioned that our study has few limitations which are the same as those of previously published bibliometric studies [51-53].

\section{Conclusion}

The present data reveals a good late momentum for breast cancer research activity from the Arab world. However, the quantity and quality of breast cancer research was low for some Arab countries. Governmental funding and survey programs are important to increase the volume of data available for research in Arab countries. No doubt that researchers in Arab countries need to invest more in the molecular biology and genetics of breast cancer among Arab in order to bridge the gap in this field of research with Israeli researchers. Higher education institutions and research centers in Arab countries should build new bridges of collaboration with their international counterparts to promote breast cancer research in Arab countries.

\section{Abbreviations}

ISI: Institute for Scientific Information; KSA: Kingdom of Saudi Arabia; USA: United States of America; JCR: Journal Citation Report; SCR: Standard Competition Ranking; IFs: Impact factors; WoS: Web of Science.

\section{Competing interests}

The authors declare that they have no competing interests.

\section{Authors' contributions}

WS led study design, data collection, statistical analysis and drafting of manuscript; SZ made part of the statistical analysis and wrote part of the article; SA and AS revised the article for important intellectual content. All authors read and approved the final manuscript and agreed on its submission.

\section{Acknowledgement}

The authors would like to express many thanks and gratitude to An-Najah University for help in conducting this study.

\section{Author details}

${ }^{1}$ Department of Pharmacology and Toxicology, College of Medicine and Health Sciences, An-Najah National University, Nablus, Palestine. ${ }^{2}$ Department of Clinical and Community Pharmacy, College of Medicine and Health Sciences, An-Najah National University, Nablus, Palestine.

Received: 21 March 2014 Accepted: 4 March 2015

Published online: 14 March 2015

\section{References}

1. Salim El, Moore MA, Al-Lawati JA, Al-Sayyad J, Bazawir A, Bener A, et al. Cancer epidemiology and control in the arab world - past, present and future. Asian Pac J Cancer Prev. 2009;10(1):3-16.

2. Wallin JA. Bibliometric methods: pitfalls and possibilities. Basic Clin Pharmacol Toxicol. 2005;97(5):261-75.

3. Bramness JG, Henriksen B, Person O, Mann K. A Bibliometric Analysis of European versus USA Research in the Field of Addiction. Research on Alcohol, Narcotics, Prescription Drug Abuse, Tobacco and Steroids 2001-2011. Eur Addict Res. 2014;20(1):16-22.

4. Hofman K, Ryce A, Prudhomme W, Kotzin S. Reporting of non-communicable disease research in low- and middle-income countries: a pilot bibliometric analysis. J Med Libr Assoc. 2006;94(4):415-20.

5. Huber JT, Gullion JS. Complementary and alternative medicine as represented in the HIV/AIDS body of knowledge: a bibliometric analysis. Med Ref Serv Q. 2003;22(3):23-32.

6. Rashidi A, Rahimi B, Delirrad M. Bibliometric analysis of parasitological research in iran and Turkey: a comparative study. Iran J Parasitol. 2013;8(2):313-22.

7. Zyoud SH, Al-Jabi SW, Sweileh WM, Awang R. Assessing the scientific research productivity of a leading toxicology journal: A case study of Human \& Experimental Toxicology from 2003 to 2012. SAGE Open Med. 2014;2:2050312114523424.

8. Zyoud SH, Al-Jabi SW, Sweileh WM. Worldwide research productivity of paracetamol (acetaminophen) poisoning: a bibliometric analysis (2003-2012). Hum Exp Toxicol. 2014;34(1):12-23.

9. Zyoud SH, Al-Jabi SW, Sweileh WM, Awang R. A bibliometric analysis of toxicology research productivity in Middle Eastern Arab countries during a 10-year period (2003-2012). Health Res Policy Syst. 2014;12(1):4.

10. Sweileh WM, Al-Jabi SW, Zyoud SH, Sawalha AF, Ghanim MA. Osteoporosis is a neglected health priority in Arab World: a comparative bibliometric analysis. Springer Plus. 2014;3(1):427

11. Sweileh WM, Zyoud SH, Al-Jabi SW, Sawalha AF. Assessing urology and nephrology research activity in Arab countries using ISI web of science bibliometric database. BMC Res Notes. 2014;7(1):258.

12. Sweileh WM, Zyoud SH, Al-Jabi SW, Sawalha AF. Bibliometric analysis of diabetes mellitus research output from Middle Eastern Arab countries during the period (1996-2012). Scientometrics. 2014;101(1):819-32.

13. Thomson Reuters. Web of Knowledge. 2013 [cited 2013 December 11]; Available from: http://wokinfo.com/media/pdf/SSR1 103443WoK5-2_web3.pdf

14. Sweileh WM, Al-Jabi SW, Sawalha AF, Zyoud SH. Bibliometric analysis of nutrition and dietetics research activity in Arab countries using ISI Web of Science database. Springer Plus. 2014;3(1):718. 
15. Sweileh WM, Zyoud SH, Al-Jabi SW, Sawalha AF. Substance use disorders in Arab countries: research activity and bibliometric analysis. Subst Abuse Treat Prev Policy. 2014;9:33.

16. Perez-Santos JL, Anaya-Ruiz M. Mexican breast cancer research output, 2003-2012. Asian Pac J Cancer Prev. 2013;14(10):5921-3.

17. Glynn RW, Scutaru C, Kerin MJ, Sweeney KJ. Breast cancer research output, 1945-2008: a bibliometric and density-equalizing analysis. Breast Cancer Res. 2010;12(6):R108.

18. Donnelly TT, Khater AH, Al-Bader SB, Al Kuwari MG, Al-Meer N, Malik M, et al. Arab women's breast cancer screening practices: a literature review. Asian Pac J Cancer Prev. 2013;14(8):4519-28.

19. Abdel-Halim RE. Contributions of Ibn Al-Nafis (1210-1288 AD) to the progress of medicine and urology. A study and translations from his medical works. Saudi Med J. 2008;29(1):13-22

20. Al-Khader AA. Enhancing research productivity in the Arab world. Saudi Med J. 2004:25(10):1323-7.

21. Benamer HT, Bredan A, Bakoush O. Scientific publication productivity of Libyan medical schools: a bibliometric study of papers listed in PubMed, 1988-2007. Educ Health (Abingdon). 2009;22(2):310.

22. Bissar-Tadmouri N, Tadmouri GO. Bibliometric analyses of biomedical research outputs in Lebanon and the United Arab Emirates (1988-2007). Saudi Med J. 2009;30(1):130-9.

23. Farhat $T$, Abdul-Sater Z, Obeid M, Arabi M, Diab K, Masri S, et al. Research in congenital heart disease: a comparative bibliometric analysis between developing and developed countries. Pediatr Cardiol. 2013;34(2):375-82

24. Benamer HT, Bakoush O. Arab nations lagging behind other Middle Eastern countries in biomedical research: a comparative study. BMC Med Res Methodol. 2009:9:26

25. Shaban SF, Abu-Zidan FM. A quantitative analysis of medical publications from Arab countries. Saudi Med J. 2003:24(3):294-6.

26. Bredan A, Benamer $H$, Bakoush O. Visibility of Arab countries in the world biomedical literature. Libyan J Med. 2011;6:6325.

27. Tadmouri GO, Bissar-Tadmouri N. Biomedical publications in an unstable region: the Arab world, 1988-2002. Lancet. 2003;362(9397):1766.

28. El-Azami-El-Idrissi M, Lakhdar-Idrissi M, Ouldim K, Bono W, Amarti-Riffi A, Hida $M$, et al. Improving medical research in the Arab world. Lancet. 2013;382(9910):2066-7.

29. Plomp R. The highly cited papers of professors as an indicator of a research group's scientific performance. Scientometrics. 1994;29(3):377-93.

30. Aksnes DW, Sivertsen $\mathrm{G}$. The effect of highly cited papers on national citation indicators. Scientometrics. 2004;59(2):213-24.

31. Aksnes DW. Citation rates and perceptions of scientific contribution. J Am Soc Inf Sci Technol. 2006;57(2):169-85.

32. Fowler $\mathrm{JH}$, Aksnes DW. Does self-citation pay? Scientometrics. 2007;72(3):427-37

33. Vinkler $\mathrm{P}$. Eminence of scientists in the light of the h-index and other scientometric indicators. J Inform Sci. 2007:33(4):481-91.

34. Jacsó P. The pros and cons of computing the h-index using Web of Science. Online Inf Rev. 2008;32(5):673-88.

35. Jacsó P. The pros and cons of computing the h-index using Scopus. Online Inf Rev. 2008:32(4):524-35.

36. Jacsó P. The pros and cons of computing the h-index using Google Scholar. Online Inf Rev. 2008;32(3):437-52.

37. Lehmann $\mathrm{S}$, Jackson AD, Lautrup BE. Measures for measures. Nature. 2006;444(7122):1003-4

38. Hirsch JE. Does the $\mathrm{h}$ index have predictive power? Proc Natl Acad Sci U S A. 2007;104(49):19193-8.

39. Garfield E. The history and meaning of the journal impact factor. JAMA. 2006;295(1):90-3.

40. Garfield E. The meaning of the impact factor. Int J Clin Health Psychol. 2003;3(2):363-9.

41. Søreide K, Winter DC. Global survey of factors influencing choice of surgical journal for manuscript submission. Surgery. 2009;147(4):475-80.

42. Schroter S. Importance of free access to research articles on decision to submit to the BMJ: survey of authors. BMJ. 2006;332(7538):394-6.

43. Lee $S$, Bozeman B. The impact of research collaboration on scientific productivity. Social Studies Sci. 2005;35(5):673-702.

44. Abramo G, D'Angelo CA, Di Costa F. Research collaboration and productivity: is there correlation? High Educ. 2009;57(2):155-71.
45. Sweileh WM, Zyoud SH, Al-Jabi SA, Sawalha AF. Quantity and quality of obesity-related research in Arab countries: assessment and comparative analysis. Health Res Policy Syst. 2014;12(1):33.

46. Bordons M, Gomez I, Fernandez MT, Zulueta MA, Mendez A. Local, domestic and international scientific collaboration in biomedical research. Scientometrics. 1996;37(2):279-95.

47. Bozeman B, Corley E. Scientists' collaboration strategies: implications for scientific and technical human capital. Res Policy. 2004;33(4):599-616.

48. Wagner CS. Six case studies of international collaboration in science. Scientometrics. 2005;62(1):3-26

49. He Z-L, Geng X-S, Campbell-Hunt C. Research collaboration and research output: A longitudinal study of 65 biomedical scientists in a New Zealand university. Res Policy. 2009;38(2):306-17.

50. Basu A, Kumar BSV. International collaboration in Indian scientific papers. Scientometrics. 2000;48(3):381-402.

51. Li XQ, Tao KM, Zhou QH, Ling CQ. Scientific publications from mainland China, Taiwan, and Hong Kong in integrative and complementary medicine journals: a ten-year literature survey. Am J Chin Med. 2011;39(4):639-49.

52. Sweileh WM, Zyoud SH, Sawalha AF, Abu-Taha A, Hussein A, Al-Jabi SW. Medical and biomedical research productivity from Palestine, 2002-2011. BMC Res Notes. 2013;6:41.

53. Zyoud SH, Al-Jabi SW, Sweileh WM, Awang R. A bibliometric analysis of research productivity of Malaysian publications in leading toxicology journals during a 10-year period (2003-2012). Hum Exp Toxicol. 2013;33(12):1284-93.

\section{Submit your next manuscript to BioMed Central and take full advantage of:}

- Convenient online submission

- Thorough peer review

- No space constraints or color figure charges

- Immediate publication on acceptance

- Inclusion in PubMed, CAS, Scopus and Google Scholar

- Research which is freely available for redistribution 